\title{
N 89-29164
}

\section{ELECTRIC OUADRUPOLE EXCITATIONS IN RELATIVISTIC NUCLEUS-NUCLEUS COLLISIONS}

\author{
by \\ John W. Norbury ${ }^{\dagger}$ \\ Physics Department \\ Washington State University \\ Pullman, WA
}

PACS: 25.70. Np

$\dagger$ This work was supported in part by NASA grant NAG-1-797. 


\section{Abstract}

Calculations are presented for electric quadrupole excitations in relativistic nucleusnucleus collisions. The theoretical results are compared to an extensive data set and it is found that electric quadrupole effects provide substantial corrections to cross sections, especially for heavier nuclei. 


\section{INTRODUCTION}

The search for a fundamentally new state of matter in the form of a Quark-Gluon Plasma ${ }^{1)}$ has stimulated the production of very high energy nuclear beams. The hope is to observe the Quark-Gluon Plasma in a relativistic nucleus-nucleus collision. At the Berkeley Bevalac a variety of light nuclei such as ${ }^{12} \mathrm{C}, 16 \mathrm{O}$ and $20 \mathrm{Ne}$ can be accelerated up to energies of $2.1 \mathrm{GeV} / \mathrm{N}$ and heavier nuclei such as ${ }^{139} \mathrm{La}$ and $238 \mathrm{U}$ can be accelerated to 1.26 and $0.96 \mathrm{GeV} / \mathrm{N}$ respectively. At Brookhaven, New York, 160 beams are available at 14.6 GeV/N and at the CERN SPS, in Geneva, beams of 160 and ${ }^{32} \mathrm{~S}$ are both produced at 60 and $200 \mathrm{GeV} / \mathrm{N}$. The Relativistic Heavy Ion Collider (RHIC) is expected to produce two colliding beams at $100 \mathrm{GeV} / \mathrm{N}$ to give a total center-of-mass energy of $200 \mathrm{GeV} / \mathrm{N}$, which corresponds to a single beam energy of $21 \mathrm{TeV} / \mathrm{N}$. Grabiak 2) has pointed out that nuclear beams of $3.5 \mathrm{TeV} / \mathrm{N}$ and $8 \mathrm{TeV} / \mathrm{N}$ may be possible at the CERN Large Hadron Collider (LHC) or the Superconducting Super Collider (SSC). By way of comparison, the majority of Galactic Cosmic Rays have energies ${ }^{3)}$ of about $1 \mathrm{GeV} / \mathrm{N}$, with a range ${ }^{3)}$ typically from $10 \mathrm{MeV} / \mathrm{N}$ to $1 \mathrm{TeV} / \mathrm{N}$. However, the JACEE collaboration ${ }^{4)}$ has made observations as high as $1000 \mathrm{TeV} / \mathrm{N}$.

Nucleus-nucleus reactions proceed mainly through either the Strong or Electromagnetic (EM) interactions. Historically, Strong interaction processes have been the main object of study 5), however with the availability of the above high energy nuclear beams there has been a resurgence of interest in EM interactions in relativistic nucleus-nucleus collisions. 6)

The primary theoretical tool for studying these relativistic EM processes has been via the Weizsäcker-Williams (WW) method ${ }^{6-7)}$ of virtual quanta. The nucleus-nucleus total EM reaction cross section is

$$
\sigma=\int N_{w w}\left(E_{\gamma}\right) \sigma\left(E_{\gamma}\right) d E_{\gamma}
$$

where $E_{\gamma}$ is the virtual photon energy, $N_{W W}(E \gamma)$ is the $W W$ virtual photon spectrum and $\sigma\left(\mathrm{E}_{\gamma}\right)$ is the photonuclear reaction cross section. For high accuracy it is important to use experimental photonuclear data for $\sigma\left(\mathrm{E}_{\gamma}\right)$. (For an excellent compilation of photoneutron 
data see reference 8.) However, a more exact formulation of $\sigma$ involves a breakdown into the various EM multipolarities such as electric dipole (E1), electric quadrupole (E2), magnetic dipole (M1) etc. The most important contributions to $\sigma$ are from E1 and E2 so that

$$
\begin{aligned}
\sigma & =\sigma_{\mathrm{E} 1}+\sigma_{\mathrm{E} 2} \\
& =\int\left[\mathrm{N}_{\mathrm{E} 1}\left(\mathrm{E}_{\gamma}\right) \sigma_{\mathrm{E} 1}\left(\mathrm{E}_{\gamma}\right)+\mathrm{N}_{\mathrm{E} 2}\left(\mathrm{E}_{\gamma}\right) \sigma_{\mathrm{E} 2}\left(\mathrm{E}_{\gamma}\right)\right] d \mathrm{E}_{\gamma}
\end{aligned}
$$

where $\mathrm{N}_{\mathrm{Ei}}\left(\mathrm{E}_{\gamma}\right)$ is the virtual photon spectrum of a particular multipolarity due to the projectile nucleus and $\sigma_{\mathrm{Ei}}\left(\mathrm{E}_{\gamma}\right)$ is the photoriuclear reaction cross section of the target nucleus. Bertulani and Baur $\left.{ }^{6}\right)$ have derived expressions for $\mathrm{N}_{\mathrm{Ei}}\left(\mathrm{E}_{\gamma}\right)$ and found that the electric dipole spectrum is the same as the WW spectrum, i.e. $N_{E 1}\left(E_{\gamma}\right)=N_{W W}\left(E_{\gamma}\right)$. Furthermore at very high projectile energies all $\mathrm{N}_{\mathrm{Ei}}\left(\mathrm{E}_{\gamma}\right)$ and $\mathrm{N}_{\mathrm{Mi}}\left(\mathrm{E}_{\gamma}\right)$ are equal so that equation (1) is seen to be a very high energy approximation to all multipolarities included in equation (2). Bertulani and Baur ${ }^{6}$ ) have made a crude estimate of the EM cross section using equation (2) but they pulled $\mathrm{N}_{\mathrm{E} 1}\left(\mathrm{E}_{\gamma}\right)$ and $\mathrm{N}_{\mathrm{E} 2}\left(\mathrm{E}_{\gamma}\right)$ outside the integral and evaluated them at a single energy and used sum rules to evaluate $\int \sigma_{\mathrm{Ei}}\left(\mathrm{E}_{\gamma}\right) \mathrm{dE} \mathrm{E}_{\gamma}$. However, this procedure did not yield very accurate results. Thus I undertook a more exact study ${ }^{9)}$ leaving equation (2) as it stands, and using experimental data for the photonuclear cross sections by defining

$\sigma_{\mathrm{E} 1}\left(\mathrm{E}_{\gamma}\right) \equiv \sigma_{\text {expt. }}\left(\mathrm{E}_{\gamma}\right)-\sigma_{\mathrm{E} 2}\left(\mathrm{E}_{\gamma}\right)$

where $\sigma_{\text {expt. }}\left(\mathrm{E}_{\gamma}\right)$ is the experimentally measured photonuclear cross section and $\sigma_{\mathrm{E} 2}\left(\mathrm{E}_{\gamma}\right)$ is a theoretical calculation based on a Lorentzian shape for the Electric Giant Quadrupole Resonance (GQR). Details for this procedure can be found in reference 9. As was noted in that reference, the above procedure yields very accurate values for the sum $\sigma_{\mathrm{E} 1}+\sigma_{\mathrm{E} 2}$ (which is to be compared to nucleus-nucleus reaction experiments) even though the GQR parameters are uncertain. The basic reasor. for this, as can be seen from equation (3), is 
that an under (over) estimate in $\sigma_{\mathrm{E} 2}\left(\mathrm{E}_{\gamma}\right)$ will give an over (under) estimate in $\sigma_{\mathrm{E} 1}(\mathrm{E} \gamma)$, so that the combined $\sigma_{\mathrm{E} 1}+\sigma_{\mathrm{E} 2}$ in equation (2) will not change very much.

In reference 9 a detailed study of $\mathrm{E} 1$ and E2 was undertaken for the reaction ${ }^{89} \mathrm{Y}$ (RHI, X) ${ }^{88} \mathrm{Y}$ where $\mathrm{RHI}$ refers to various Relativistic Heavy Ions and $\mathrm{X}$ is anything. It was found that E2 effects account for a considerable fraction of the cross section, and that inclusion of E2 (via equation 2) provides improved agreement with experiment over the WW method. Given this situation, it was decided to compare this theoretical approach to as much experimental data as possible. Thus the present work involves a comparison to neutron emission from ${ }^{89} \mathrm{Y},{ }^{197} \mathrm{Au},{ }^{59} \mathrm{Co}$ and neutron and proton emission from ${ }^{12} \mathrm{C}, 16 \mathrm{O}$ and 180 which includes both electric dipole and quadrupole effects. This complements earlier work ${ }^{7)}$ which involved an extensive comparison of WW theory to experiment.

\section{CALCULATIONAL METHOD}

The basic calculational method is outlined in reference 9 and the discussion will not be repeated here. Also reference 7 includes a very detailed summary of which photonuclear data were used for $\sigma_{\text {expt. }}(\mathrm{E} \gamma)$ in equation (3). The same data is used in the present work. All isoscalar GQR parameters were taken from the compilation of Bertrand ${ }^{10)}$ and are listed in Table 1. As mentioned in the Introduction, even though these parameters are somewhat uncertain the total EM cross section $\sigma_{\mathrm{E} 1}+\sigma_{\mathrm{E} 2}$ is expected to be very accurate 9 ) due to the subtraction procedure of equation (3). The most inaccurate results would be expected for the ${ }^{12} \mathrm{C}, 16 \mathrm{O}, 18 \mathrm{O} \mathrm{GQR}$ parameters where the isoscalar GQR is fragmented into several components 10 ). Only a single Lorentzian 9) was 
Table 1: Isoscalar Giant Quadrupole Resonance (GQR) Parameters taken from the compilation of Bertrand 10 ). $E$ is the GQR resonance excitation energy, $\Gamma$ is the full-width at half maximum and $f$ is the fractional depletion of the Energy Weighted Sum Rule. (The GQR of light nuclei are fragmented into several peaks, so that the parameters below represent an estimated average value.)

$\begin{array}{cccc}\text { Nucleus } & \begin{array}{c}\mathbf{E} \\ (\mathbf{M e V})\end{array} & \begin{array}{c}\Gamma \\ (\mathbf{M e V})\end{array} & \mathbf{f} \\ { }^{12} \mathrm{C} & 27.5^{\mathrm{a}} & 3.0^{\mathrm{b}} & 0.4^{\mathrm{d}} \\ { }^{16 \mathrm{O}} & 22.0^{\mathrm{b}} & 3.0^{\mathrm{c}} & 0.4^{\mathrm{d}} \\ { }^{18 \mathrm{O}} & 24.0^{\mathrm{a}} & 3.0^{\mathrm{c}} & 0.4^{\mathrm{c}} \\ { }^{59} \mathrm{Co} & 16.3^{\mathrm{b}} & 5.6^{\mathrm{b}} & 0.61^{\mathrm{b}} \\ { }^{89} \mathrm{Y} & 13.8^{\mathrm{b}} & 3.2^{\mathrm{b}} & 0.55^{\mathrm{d}} \\ { }^{197} \mathrm{Au} & 10.8^{\mathrm{a}} & 2.9^{\mathrm{b}} & 0.95^{\mathrm{d}}\end{array}$
a $\mathrm{E}$ is calculated from $63 \mathrm{~A}^{-1 / 3}$
b best value taken from Table 4 of ref. 10
c estimate
d from Fig 23 of ref. 10

used in the present work. However $\sigma_{\mathrm{E} 2}$ is found to be quite small for these nuclei (see below) so that my conclusion that the calculated $\sigma_{\mathrm{E} 1}+\sigma_{\mathrm{E} 2}$ is accurate remains valid.

For the nuclei ${ }^{12} \mathrm{C},{ }^{16} \mathrm{O}$ and ${ }^{18} \mathrm{O}$, proton (p) emission occurs as well as neutron (n) emission. Thus equation (3) needs to be modified to incorporate the branching ratio. I assume that the excited nucleus decays only by proton or neutron emission and that the (photon) energy dependent neutron branching ratio is defined as

$$
f_{n}\left(E_{\gamma}\right) \equiv \frac{\sigma_{\text {expt }}\left(E_{\gamma}, n\right)}{\sigma_{\text {expt }}\left(E_{\gamma}, n\right)+\sigma_{\text {expt }}\left(E_{\gamma}, p\right)}
$$

so that 


$$
\sigma_{\mathrm{E} 2}\left(E_{\gamma}, \mathrm{n}\right)=\mathrm{f}_{\mathrm{n}}\left(\mathrm{E}_{\gamma}\right) \sigma_{\mathrm{E} 2}\left(\mathrm{E}_{\gamma}\right)
$$

where $\sigma_{\mathrm{E} 2}\left(\mathrm{E}_{\gamma}\right)$ is the photonuclear $\mathrm{GQR}$ cross section. Thus for proton and neutron emission equation (3) becomes

$$
\sigma_{\mathrm{E} 1}\left(E_{\gamma}, n\right)=\sigma_{\text {expt. }}(E \gamma, n)-f_{n}\left(E_{\gamma}\right) \sigma_{E 2}\left(E_{\gamma}\right)
$$

and

$$
\sigma_{E 1}\left(E_{\gamma}, p\right)=\sigma_{\text {expt. }}(E \gamma, p)-\left[1-f_{n}\left(E_{\gamma}\right)\right] \sigma_{E 2}\left(E_{\gamma}\right)
$$

Equations (4) - (6) were used for nucleon emission from ${ }^{12} \mathrm{C},{ }^{16} \mathrm{O}$ and ${ }^{18 \mathrm{O}}$. For ${ }^{59} \mathrm{Co}$, the $(\gamma, p)$ cross section is not available and so a constant value of $f_{n}=0.7$ (suggested from reference 11) was used. For ${ }^{89} \mathrm{Y}$ and ${ }^{197} \mathrm{Au}$ I used $\mathrm{f}_{\mathrm{n}}=1.0$.

\section{RESULTS AND DISCUSSION}

The calculated results are listed in Table 2, along with the experimental results of various groups. ${ }^{12-16)} \sigma_{\mathrm{E} 1}+\sigma_{\mathrm{E} 2}$ is the calculated result to be compared with the data $\sigma_{\text {expt. }}$ Also listed are the results of WW calculations. ${ }^{7)}$ In all cases two theoretical cross sections are listed. The first is calculated using an expression for the minimum impact parameter as

$$
b_{\min }=R_{0 \cdot 1}(T)+R_{0 \cdot 1}(P)
$$

where $R_{0.1}$ represents the 10-percent charge density radius 7) of the target or projectile. The second theoretical cross section listed in parentheses in Table 2 uses $b_{\min }$ given by Hill et al. ${ }^{14-16)}$ as

$$
b_{\min }=r_{0}\left[A_{p}^{1 / 3}+A_{T}^{1 / 3}-X\left(A_{p}^{-1 / 3}+A_{T}^{-1 / 3}\right]\right.
$$

where $r_{0}=1.34 \mathrm{fm}$ and $X=0.75$. (Note that my WW calculations disagree with earlier results of Hill et al. 14-16) due to an error in their calculations. 19-20))

There are several features readily apparent from Table 2;

(i) $\sigma_{\mathrm{E} 1}+\sigma_{\mathrm{E} 2}$ is always larger than $\sigma_{\mathrm{Ww}}$. However, for nucleon emission from ${ }^{12} \mathrm{C}$, 160 and ${ }^{18} \mathrm{O}$ this difference is never larger than about $4 \%$, but for neutron emission from ${ }^{59} \mathrm{Co},{ }^{89} \mathrm{Y}$ and ${ }^{197} \mathrm{Au}$ the difference is much larger varying between about $7 \%-15 \%$. 
ii) For nucleon emission from ${ }^{12} \mathrm{C}$ and ${ }^{16} \mathrm{O}$ both $\sigma_{\mathrm{E} 1}+\sigma_{\mathrm{E} 2}$ and $\sigma_{\mathrm{WW}}$ agree with experiment for both choices of $b_{\min }$.

iii) For nucleon emission from ${ }^{18} \mathrm{O}$ both $\sigma_{\mathrm{E} 1}+\sigma_{\mathrm{E} 2}$ and $\sigma_{\mathrm{WW}}$ disagree with experiment for both choices of bmin. $\sigma_{\mathrm{WW}}$ actually gives slightly better agreement but not by a significant amount.

iv) For neutron emission from ${ }^{197} \mathrm{Au}, \sigma_{\mathrm{E} 1}+\sigma_{\mathrm{E} 2}$ is significantly closer to experimental values than is $\sigma_{W W}$, although for most cases it still lies outside the error bars. An exception however is a much poorer agreement for ${ }^{139} \mathrm{La}$ (see also references 19 and 20 ). Significant discrepancies with ${ }^{197} \mathrm{Au}$ data have been noted previously for WW theory.7)

v) For neutron emission from ${ }^{89} \mathrm{Y}, \sigma_{\mathrm{E} 1}+\sigma_{\mathrm{E} 2}$ is in much better agreement with experiment than is $\sigma_{\mathrm{Ww}}$. This is especially true for the ${ }^{40} \mathrm{Ar}$ and ${ }^{56} \mathrm{Fe}$ projectiles.

vi) For ${ }^{59} \mathrm{Co}, \sigma_{\mathrm{E} 1}+\sigma_{\mathrm{E} 2}$ is again better for ${ }^{20 \mathrm{Ne}}$, although slightly worse for ${ }^{56} \mathrm{Fe}$. As above the agreement for the ${ }^{139} \mathrm{La}$ projectile is significantly poorer.

\section{SUMMARY AND CONCLUSIONS}

Calculations have been made for nucleon emission via EM dissociation in relativistic nucleus-nucleus collisions. Results are presented for Weizsäcker-Williams theory and also for separate electric dipole and quadrupole components. The theories have been compared to an extensive data set. It is found that electric quadrupole (E2) effects are not significant for proton and neutron emission from ${ }^{12} \mathrm{C},{ }^{16} \mathrm{O}$ or ${ }^{18} \mathrm{O}$. However, E2 contributions are substantial for neutron emission from ${ }^{59} \mathrm{Co},{ }^{89} \mathrm{Y}$ and ${ }^{197} \mathrm{Au}$, generally leading to improved agreement between theory and experiment. Notable disagreements occur for ${ }^{139} \mathrm{La}$ projectiles $(1.26 \mathrm{GeV} / \mathrm{N})$ where the theoretical $\sigma_{\mathrm{E} 1}+\sigma_{\mathrm{E} 2}$ are too big. Quadrupole effects improve the theoretical results for 160 projectiles at 60 and $200 \mathrm{GeV} / \mathrm{N}$, although the theoretical cross sections are still too small.

In general it has been found that electric quadrupole effects are an important component in nucleus-nucleus collisions and that these effects can be calculated accurately. 


\section{ACKNOWLEDGEMENTS}

I wish to thank Larry Townsend for useful discussions and Gayle Norbury for help with the photonuclear data. 


\section{REEERENCES}

1. K. Kajantie and L. McLerran, Ann. Rev. Nucl. Part. Sci. $\underline{37} 293$ (1987).

2. M. Grabiak, B. Muller, W. Greiner, G. Soff and P. Koch, J. Phys. G 15 L25 (1989).

3. J. A. Simpson, Ann. Rev. Nucl. Part. Sci. $\underline{33} 323$ (1983).

4. W. V. Jones, Y. Takahashi, B. Wosiek and O. Miyamura, Ann. Rev. Nucl. Part. Sci. $\underline{37} 71$ (1987).

5. W. G. Lynch, Ann. Rev. Nucl. Part. Sci. 37493 (1987).

6. C. A. Bertulani and G. Baur, Phys. Rep. 163299 (1988).

7. J. W. Norbury, "Nucleon Emission via Electromagnetic Excitation in Relativistic Nucleus-Nucleus Collisions: Re-analysis of the Weizsäcker-Williams Method" Phys. Rev. C (in press).

8. S. S. Dietrich and B. L. Berman, Atomic Data and Nuclear Data Tables $\underline{38} 199$ (1988).

9. J. W. Norbury, "Electric Quadrupole Excitations in the Interactions of ${ }^{89} \mathrm{Y}$ with Relativistic Nuclei," Phys. Rev. C (in press).

10. F. E. Bertrand, Ann. Rev. Nucl. Sci. 26457 (1976).

11. J. W. Norbury, F. A. Cucinotta, L. W. Townsend and F. F. Badavi, Nucl. Inst. Meth. Phys. Res. B 31535 (1988).

12. H. H. Heckman, and P. J. Lindstrom, Phys. Rev. Lett. 37, 56 (1976).

13. D. L. Olson, B. L. Berman, D. E. Greiner, H. H. Heckman, P. J. Lindstrom, G. D. Westfall, and H. J. Crawford, Phys. Rev. C 24, 1529 (1981).

14. M. T. Mercier, J. C. Hill, F. K. Wohn, C. M. McCullough, M. E. Nieland J. A. Winger, C. B. Howard, S. Renwick, D. K. Matheis and A. R. Smith, Phys. Rev. C 331655 (1986).

15. J. C. Hill, F. K. Wohn, J. A. Winger, and A. R. Smith, Phys. Rev. Lett. 60999 (1988).

16. J. C. Hill, F. K. Wohn, J. A. Winger, M. Khayat, K. Leininger, and A. R. Smith, Phys. Rev. C 381722 (1988).

17. A Lepretre, H. Beil, R. Bergere, P. Carlos, A. Veyssiere and M. Sugawara, Nucl. Phys. A 175609 (1971).

18. B. L. Berman, R. E. Pywell, S. S. Dietrich, M. N. Thompson, K. G. McNeill and J. W. Jury, Phys. Rev. C 361286 (1987).

19. J. W. Norbury, Phys. Rev. C $\underline{39} 2472$ (1989).

20. J. C. Hill and F. K. Wohn, Phys. Rev. C 392474 (1989). 


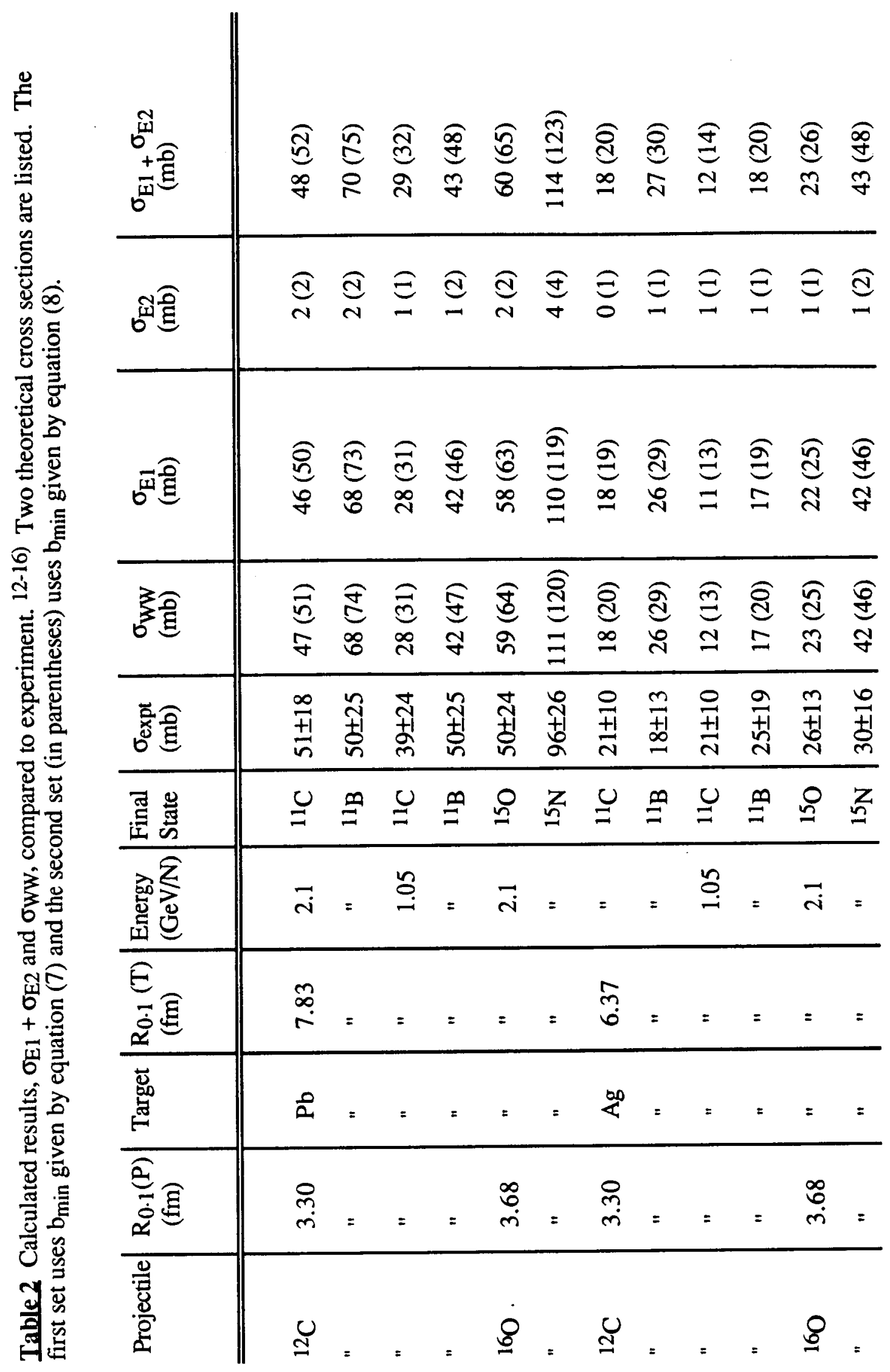




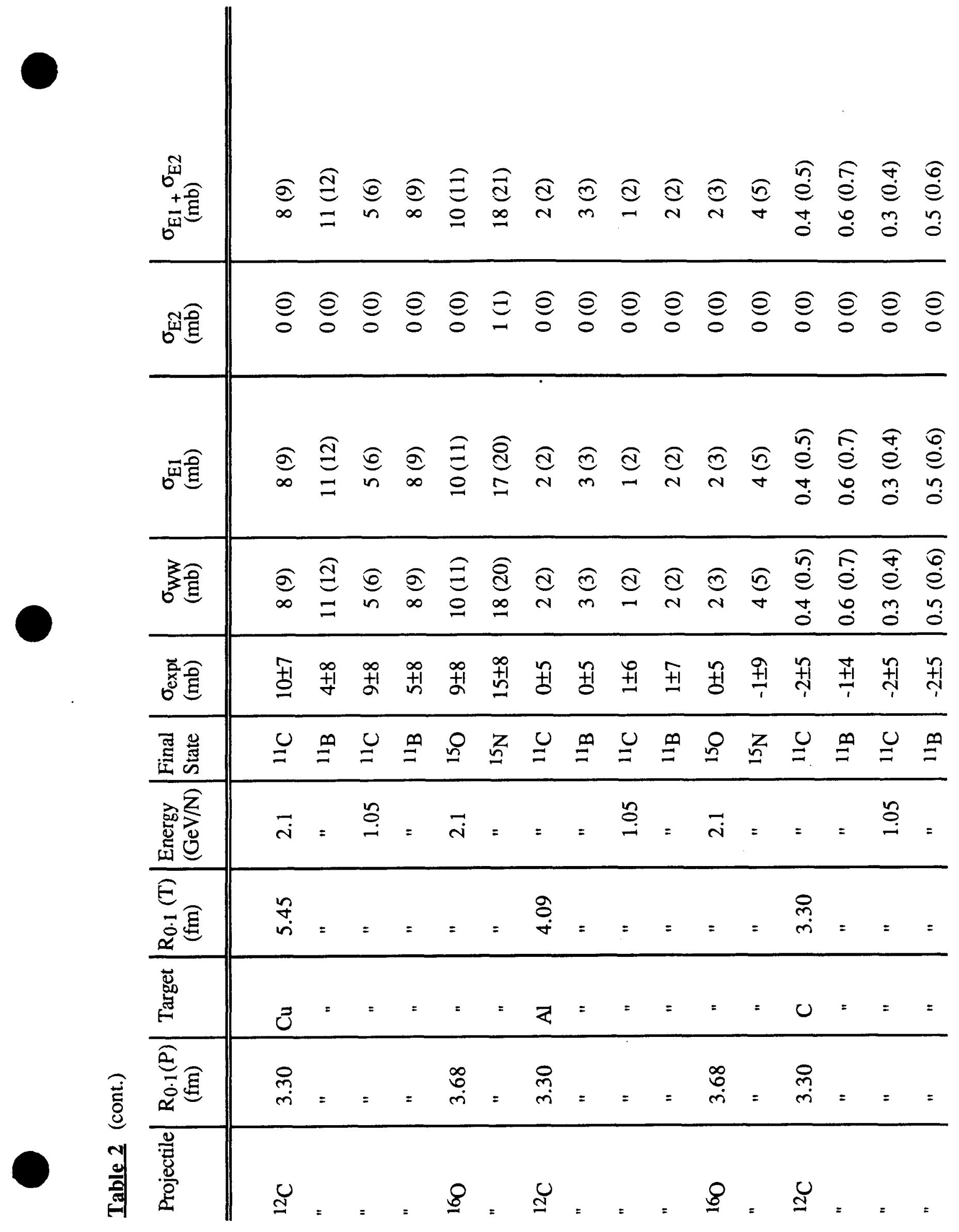




\begin{tabular}{|c|c|c|c|c|c|c|c|c|}
\hline 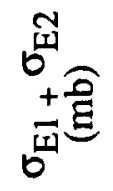 & 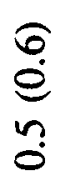 & $\Xi$ & $\underset{n}{E}$ & $\frac{\widehat{n}}{m}$ & $\begin{array}{l}\underset{\infty}{\infty} \\
\stackrel{\infty}{=} \\
\stackrel{n}{=}\end{array}$ & 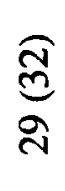 & 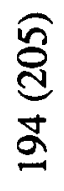 & 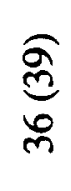 \\
\hline 펌로 & $\stackrel{\varrho}{0}$ & త్ర & $\underset{\Xi}{\Xi}$ & $\stackrel{\varrho}{0}$ & $\underset{\forall}{\mathcal{J}}$ & $\underset{d}{d}$ & $\underset{n}{n}$ & $\underset{m}{\approx}$ \\
\hline छี & $\underset{\substack{0 \\
0}}{\stackrel{0}{0}}$ & $\Xi$ & $\underset{n}{\sigma}$ & $\underset{m}{\widehat{m}}$ & 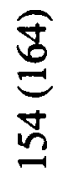 & 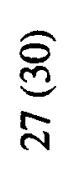 & $\begin{array}{l}\text { ళ్ర } \\
\text { ᄋ్త }\end{array}$ & $\underset{m}{\stackrel{్}{m}}$ \\
\hline 하을 & $\begin{array}{l}6 \\
\stackrel{0}{0} \\
\tilde{0}\end{array}$ & $\Xi$ & $\underset{n}{\stackrel{0}{\rightleftarrows}}$ & $\frac{\widehat{c}}{m}$ & $\begin{array}{l}\sqrt{2} \\
\stackrel{2}{n}\end{array}$ & 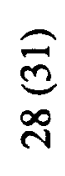 & $\begin{array}{l}\widehat{\widehat{d}} \\
\frac{\sigma}{2}\end{array}$ & $\underset{\tilde{m}}{\stackrel{\tilde{m}}{\sigma}}$ \\
\hline 坣㑒 & $\frac{\pi}{7}$ & $\frac{+}{ \pm}$ & $\begin{array}{r}n \\
+1 \\
\infty\end{array}$ & $\begin{array}{l}0 \\
\dot{1} \\
\text { 五 } \\
\dot{1}\end{array}$ & 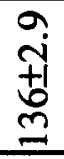 & 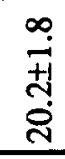 & $\begin{array}{l}\overrightarrow{+} \\
+1 \\
0 \\
0 \\
\dot{0} \\
\end{array}$ & 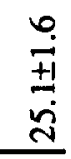 \\
\hline 胥营 & 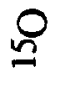 & $z$ & $\stackrel{9}{=}$ & $\underline{z}$ & $\stackrel{0}{=}$ & $\underline{z}$ & $\cong$ & $\underline{Z}$ \\
\hline 勇文 & $\vec{i}$ & $=$ & $\Xi$ & $=$ & $=$ & $=$ & $=$ & $=$ \\
\hline$\stackrel{E}{\dot{E}}$ & mे & $=$ & $\begin{array}{l}8 \\
\text { in }\end{array}$ & $=$ & $\stackrel{\infty}{\infty}$ & $=$ & $\underset{\infty}{\infty}$ & $=$ \\
\hline 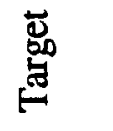 & $u$ & $=$ & 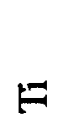 & $=$ & $\vec{\Delta}$ & $=$ & $D$ & $=$ \\
\hline$\underset{\mathscr{\varepsilon}}{\stackrel{\underline{\varepsilon}}{\mathbf{E}}}$ & $\begin{array}{l}\infty \\
0 \\
\dot{m}\end{array}$ & $=$ & $\stackrel{\infty}{r}$ & $=$ & $=$ & $=$ & $=$ & $=$ \\
\hline 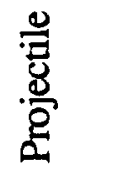 & $\stackrel{8}{8}$ & $=$ & $\$$ & $=$ & 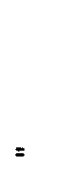 & $=$ & $=$ & 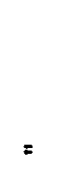 \\
\hline
\end{tabular}




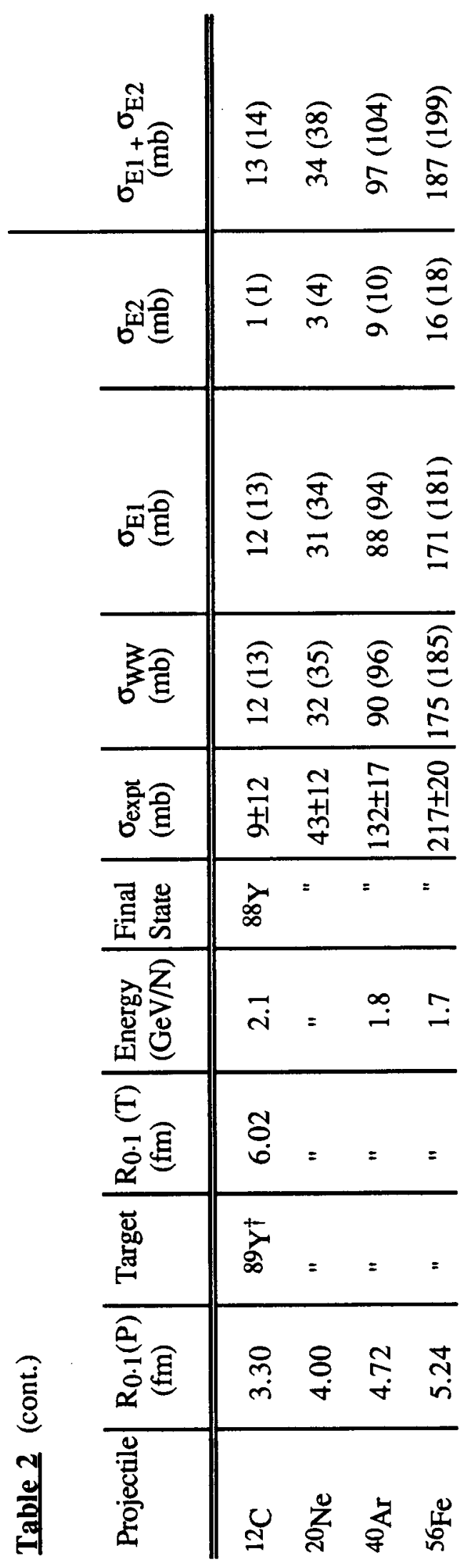




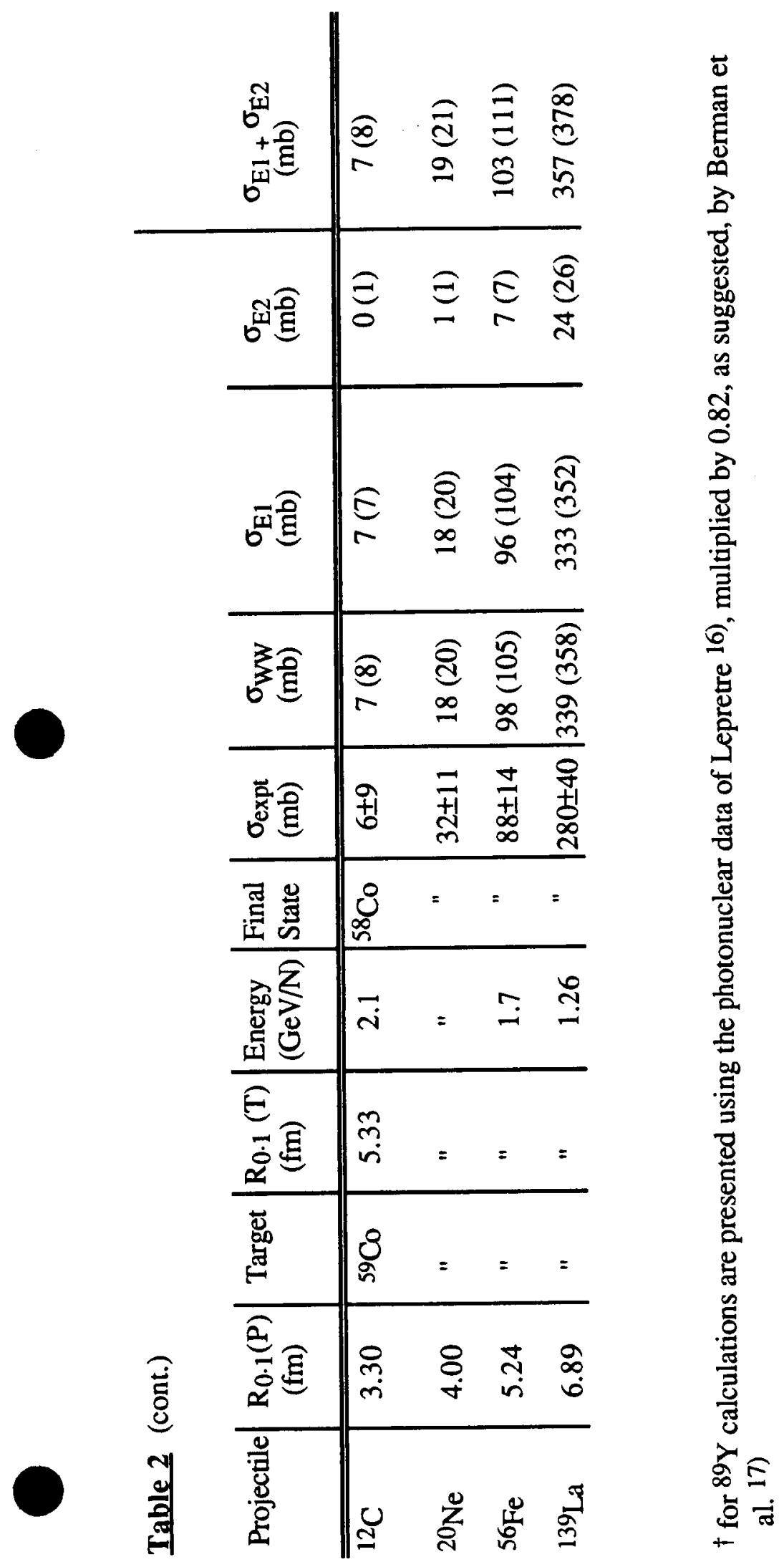

